\title{
Mangia che te fa bene! ${ }^{1}$ Comida e identidade entre os descendentes de imigrantes italianos no Rio Grande do Sul
}

\author{
Maria Catarina C. Zanini * \\ Miriam de Oliveira Santos **
}

Nosso objetivo por meio deste artigo é analisar as relações entre comida, comensalidades (WOORTMAN, 2007) e algumas especificidades da produção de identidades entre descendentes de imigrantes italianos no sul do Brasil quando tais elementos entram em diálogo. O ponto de partida foram as pesquisas etnográficas de Santos (2004) e Zanini (2006) realizadas, respectivamente, nas regiões serrana e central do Rio Grande do Sul. Nessas pesquisas se observou o quanto a produção, a circulação e o consumo de "comidas" é algo complexo e importante para estes descendentes, promovendo uma discursividade própria e reconhecida como "nativa". Talvez porque um dos motivos impulsionadores do processo migratório, ocorrido em finais do século XIX, tenha sido as péssimas condições de vida (e alimentares) que tinham na Itália, a comida e a mesa farta se tornaram símbolos adscritivos das italianidades, em que os alimentos devem ser interpretados como fruto do trabalho, valor altamente positivado entre os imigrantes e seus descendentes (vide SANTOS e ZANINI, 2009)2.

Por comida, entende-se aqui aqueles alimentos processados culturalmente e que adquirem tal status. Nas colônias italianas ${ }^{3}$, os colonos seriam, segundo Seyferth (1993), além de trabalhadores da terra, pessoas que se autoatribuíam e

\footnotetext{
* Doutora em Antropologia Social pela USP, Profa. da UFSM e Pesquisadora Associada ao NIEM.

** Doutora em Antropologia Social pela UFRJ, Profa. da UFRRJ e Pesquisadora Associada ao NIEM.
} 
reivindicavam uma origem distinta: nos casos aqui estudados, a origem italiana. O que nos importa ressaltar, neste texto, é o caráter processual e dinâmico dessas relações em que gostos, produtos e relações se encontram e como elas podem, ao longo do tempo, serem alteradas e negociadas em suas estruturas de significado gerando, nesse percurso, construções identitárias, de memórias e também novas estruturas de significado e de papéis sociais. Por memórias, entendemos, inspiradas em Halbwachs (1990), as leituras sobre o passado que são elaboradas no presente, partindo dos lugares dos narradores nos contextos contemporâneos.

A comida e a importância a ela atribuída foi algo que se fez extremamente presente em ambas as pesquisas etnográficas, mesmo não sendo inicialmente o objeto de investigação das autoras. No estudo dos processos identitários étnicos, o que se observou foi a constante presença dos elementos alimentares, suas disputas, negociações e riqueza de narrativas. Compactuamos com Mintz (2001, p. 31), ao assinalar que o comportamento relacionado à comida está diretamente associado ao "sentido de nós mesmos e à nossa identidade social". Além disso, é importante salientar que os imigrantes tendem a ser importantes agentes de mudanças dietárias também (MINTZ 2002, p. 105), reelaborando e trazendo mudanças importantes na escolha dos ingredientes, na aceitação dos sabores e no equilíbrio disto com o que seria considerado "tradicional" dos grupos de origem. Estas reelaborações efetuadas nas terras hospedeiras acabam gerando novas técnicas e apreciação de sabores, o que nem sempre é percebido pelos produtores e consumidores de tais comidas, que as reinterpretam continuadamente como "tradicionais", embora tenham sido historicamente reelaboradas. O que se observa é uma forma de transformar a comida em símbolo de resistência também (vide POULAIN, 2006). A produção da uva, por exemplo, por questões climáticas e de solo, não obteve sucesso na região central do estado, o que faz com que esta fruta não tenha o peso simbólico que adquiriu na serra gaúcha, onde se converteu em fonte de renda para as famílias de imigrantes e seus descendentes e falar em imigração italiana significa falar de uvas e vinhos.

Ambas as pesquisadoras observaram o importante papel desempenhado pelas mulheres, especialmente as mais idosas, que eram as responsáveis (agentes) pela aceitação ou não dos novos elementos culinários e a forma como estes deveriam ingressar nas hortas, roças, cozinhas, mesas e se tornarem produtos para o comércio (ou não), como os grostolis ${ }^{4}$, por exemplo, ou as massas e capelettis ${ }^{5}$ (com os quais se faz a sopa de agniolini). Muitas das entrevistas concedidas às autoras foram efetuadas em cozinhas, entre café, chá, pães, bolachas e chimarrão. Como ressalta Poulain (2006, p. 256), a cozinha é o conjunto de operações simbólicas e de rituais que, mesclados às ações técnicas, findam por construir determinada identidade alimentar e também onde um produto da natureza se converte em consumível (em comida). É nestas cozinhas que muitas negociações entre o que seria tradicional e o que seria moderno 
e suas significações são efetuadas. A cozinha, em muitos aspectos, convertese, com certeza, num espaço de resistência e reflexividade acerca das origens italianas.

Ressaltamos, contudo, que as italianidades são complexas, situacionais e devem ser observadas em suas particularidades histórico-sociais específicas. Não pretendemos aqui esboçar generalizações acerca das relações entre comidas e identidades italianas, mesmo porque encontramos muitas diferenças em nossos campos. Embora as narrativas partam de uma identificação e de um gosto considerado naturalizado, o que observamos foram comidas produzidas nos encontros culturais, seja na serra gaúcha ou na região central do Rio Grande do Sul. Embora italianos, num sentido genérico, os gostos e as práticas alimentares têm suas especificidades, diversidade e construções narrativas específicas.

Nesta conjugação, pensamos como Maciel (2001, p. 151), ao destacar o quanto a comida está envolvida com emoção e "trabalha com a memória e com sentimentos" e também com os pertencimentos. Assim, nestas inter-relações, não se pode perder de vista o peso das subjetividades, bem como o das forças sociais e suas negociações. Zanini (2006) observou o importante papel da comida no processo de construção das memórias coletivas dos descendentes por ela estudados. Nas narrativas coletadas pela pesquisadora, comumente a comida aparecia mesclada a acontecimentos e situações importantes para os indivíduos e suas famílias. Os casamentos, batizados e outros eventos eram narrados se apresentando também o que fora comido na ocasião. As relações sociais, as trajetórias individuais e familiares se cruzavam com a produção e o consumo de alimentos. Em narrativas de mulheres idosas, era comumente ressaltado o tempo de preparo para bolachas, doces para casamentos e outras comidas que faziam parte de momentos especiais e diferenciados da vida dos imigrantes e seus descendentes, especialmente entre habitantes do mundo rural, da colônia. Outro elemento associado à produção eram as redes de solidariedade que tais comensalidades promoviam, agregando parentes e afins de graus diversos. As latas de bolachas, o preparo das massas, das carnes, das saladas, os doces para crianças recebiam elevado teor de significação nas falas. Algumas fotografias foram apresentadas à pesquisadora para enriquecer as narrativas e salientar a importância das comidas em determinados rituais.

Na conformação do habitus italiano (BOURDIEU, 1983), as comensalidades se apresentam como elemento fundamental na conformação dos gostos. Pelas orientações das mães italianas ${ }^{6}$, os filhos aprendem as distinções sociais que 0 comer implica: o homem se alimenta primeiro, a mulher prepara o alimento, os filhos menores esperam os mais velhos se servirem, os melhores alimentos são para vender, para a Igreja ou para as visitas, somente depois a família ${ }^{7}$ se alimenta. Ou seja, as culturas não elegem apenas aquilo que é bom para comer, mas também como devemos comê-lo, quando, de qual forma e com quem. Douglas (1971, p. 61) destaca que muitas vezes a comida funciona como um código para as relações sociais e: "as mensagens que ela codifica serão encontradas 
no padrão de relações sociais que estão sendo expressas. A mensagem trata de diferentes graus de hierarquia, de inclusão e exclusão, de fronteiras e transações através de fronteiras" 8 .

As representações construídas em função de determinado alimento remetem não apenas ao paladar e à apresentação do prato, mas também a técnicas de preparo, estratégias de compra, modos e ocasiões de consumo em que, por vezes, são necessários longos tempos de preparo. Sendo assim os alimentos “(...) são utilizados em conformidade às representações sociais e usos compartilhados pelos membros de uma classe, grupo ou cultura; (...)" (FISCHLER, 2001, p. 81)

Enfim, por meio das comensalidades uma ordem de mundo, uma visão de mundo e também um ethos (GEERTZ, 1989) finda por ser socializado e transmitido. Importante ressaltar que, no meio camponês dos descendentes de italianos, por exemplo, há pouco tempo, o domínio destas regras era requisito para as sogras aceitarem ou não uma nora. Todo um domínio e conhecimento sobre os alimentos era requisito necessário para que um indivíduo se considerasse socialmente apto para casar e constituir família. Assim, poderia se esperar dele que fosse capaz de alimentar e cuidar de uma família, em suas variadas formas. Entre os descendentes de imigrantes italianos há muitos modos de se testar se uma moça seria uma boa esposa ou não e também se aceitaria ou não as regras de comensalidade da sogra, caso com ela fosse habitar. Um dos testes era a feitura de pão e também verificar se a moça dominava técnicas de horticultura, visando que, no futuro, mantivesse sua horta a fim de alimentar a família a ser formada, bem como os sogros, em caso de com estes morar. Uma das entrevistadas de Zanini, em pesquisa realizada em 2011, relatou que até os dias de hoje seu marido compara sua comida com a de sua mãe. A comida da sogra seria "forte" e a dela, mais preocupada com problemas de colesterol e diabetes, mais fraca. Seu marido, apesar de ser diabético, não consegue se adaptar às comidas "fracas" por ela preparadas, indo, por vezes à cozinha para fritar ovos com banha como sua mãe fazia.

A comida acompanha a trajetória do processo migratório de italianos e seus descendentes no Rio Grande do Sul de forma rica, horizontalizada e criativa. Ela tem dialogado, na contemporaneidade, com as mídias, que trazem novas possibilidades e produtos, com o discurso biomédico que procura alterar padrões de consumo alimentar e também gostos e com o poder aquisitivo dos descendentes, que hoje podem comprar determinados alimentos, sem necessidade de produzi-los pessoalmente. A fome ou a falta de alimento é algo comum nas narrativas acerca do processo colonizador, contudo, como ressalta Woortman (2007, p. 184), devemos considerar que a percepção social acerca do que é fome difere no tempo e no espaço. Dona Giovanna, filha de imigrantes italianos que vieram para a região central do estado nas primeiras décadas do século XX, ao comentar acerca da novela Terra Nostra ${ }^{10}$, exibida pela primeira vez na televisão nos anos de 1999/2000, ressaltou que: "A gente era pobre, pode ser que em outras famílias tivesse isso, mas eu, eu nunca vi aquela fartura, aquelas 
coisas, no meu tempo eu não vi, pode ser que tivesse família melhor." Ou seja, a novela apresentou o estereótipo construído acerca do imigrante italiano: aquele que comia bem, de forma festiva e em grandes quantidades (vide ZANINI, 2005). $\mathrm{O}$ que de fato ocorreu nos primeiros tempos do processo colonizador foi um processo de adaptação ao clima, ao solo, às culturas, o que significava, para alguns, alimento regrado e que pode ser transmitido nas narrativas como época de escassez.

\section{Imigrantes, colonizadores e observadores no sul do Brasil: a comida como trajetória interativa e adscritiva}

Quando aquelas populações saíram da Itália, no período da Grande Imigração em finais do século XIX, a Itália era um Estado Nacional recém-unificado e com diferenças regionais fortemente demarcadas. Tratava-se de um país com muitas crises (políticas, religiosas, culturais, econômicas), em que os pobres não tinham como ascender socialmente, as terras eram poucas e a migração aparentava ser uma boa possibilidade de sobrevivência e de mobilidade social (cf. ALVIM,1986 e GROSSELLI, 1987).

A Unificação italiana desencadeou uma crise econômica durante o período final do século XIX, crise esta que não abalou igualmente todas as regiões do país. O Norte foi a primeira área a ser atingida, pois ali começou a se desenvolver a industrialização, deixando os agricultores que complementavam sua renda com o trabalho artesanal sem emprego e sem ter mercado para colocar seus produtos, uma vez que os mesmos não podiam competir com os feitos pelas fábricas locais ou com os importados. Por isto, o norte da Itália forneceria as primeiras grandes levas de emigrantes, e o sul só viveria o processo de emigração mais tarde, principalmente a partir do início do século XX.

Com o agravamento das diferenças já existentes entre as regiões da Itália, criaram-se as condições para um grande movimento migratório de classes rurais para o continente Americano entre o fim do século XIX e o início do século XX. Essas classes rurais conformavam um campesinato com receios de se proletarizar e de perder o poder paterno sobre os filhos, e eram estimulados pela Igreja Católica que vinha tendo seus poderes (e saberes) questionados, além disso, as doenças e as guerras configuravam um cenário em que a migração se apresentava como uma opção promissora (cf. LORENZONI,1975 e POZZOBOM, 1997). Para o estado brasileiro, também, a imigração era um bom negócio, pois aquelas famílias iriam dinamizar as economias regionais, bem como guardar fronteiras, especialmente no Rio Grande do Sul (MACHADO, 1999), território em constantes disputas entre Portugal e Espanha.

Em 1875 tem início o processo colonizador para a região serrana do estado do Rio Grande do Sul e em 1877/78 para a região central. Aquelas populações eram formadas, em sua maioria, por famílias de camponeses pobres, católicos e provenientes do norte da Itália (vide COSTA, 1986; De BONI, 1980, 1982, 1987). A 
comida, desde o início, apresenta-se nos imaginários relatados do Novo Mundo, em que os "salames cairiam das árvores" e o queijo ralado era distribuído em sacos (cf. LORENZONI, 1975 e POZZOBON, 1997). No Brasil, almejavam tornarse proprietários de terras, senhores, algo impossível no cenário italiano do final do século XIX. E, nesta busca por autonomia, o alimento desempenhou um papel extremamente importante, seja enquanto mercadoria por eles produzida e comercializada para pagar os lotes de terras ou enquanto processo doméstico.

Conforme relata Lorenzoni (1975), jovem emigrado da Itália com sua família, que deixa registrado o processo migratório para a região central do estado, a comida foi algo extremamente importante no encontro com a América. Eram novos sabores, texturas, odores, relações novas entre alimento e corpo. As novidades, tais como a mandioca e sua farinha, o charque, as carnes e frutas, entre outros, despertarão curiosidades e também servirão como ponto de partida para o conhecimento de gostos e hábitos locais, como o chimarrão, por exemplo (LORENZONI, 1975).

O encontro com os brasileiros resultou na adoção de novos tipos de alimento, como relata Cleodes Piazza Júlio Ribeiro:

Eu sou bisneta de um dos três primeiros casais que precede a grande imigração, meu bisavô com minha bisavó e outros dois casais são conduzidos de Porto dos Guimaraens, atual Porto do Caí, até a localidade de Nova Milano.(...) Eles foram conduzidos por um índio, o barracão ainda não havia sido construído, eles foram abrigados na choupana deste índio.(...) Luís era o nome de branco do índio, eles o chamavam de Luís Bugre e nas mitologias familiares, este Luís Bugre sempre foi uma influência extremamente positiva na relação, ele os ensinou a comer o pinhão ${ }^{11}$.

Para sobreviverem em terras brasileiras, desde o início, foram negociando as novas possibilidades alimentares em suas "estruturas de significado" (GEERTZ, 1989). Ao longo do processo colonizador, vários alimentos foram transformados e adaptados, como a polenta (mingau salgado, duro, feito da mistura de água quente com farinha de milho); a minestra (sopa de feijão com sobras de comida das refeições anteriores) e a fortaia (omelete com misturas variadas, como salame e queijo, por exemplo). Contudo, há que se observar que a generalização e a estereotipia acerca dos hábitos alimentares, por vezes, incomoda os descendentes, como o de "gringo polenteiro" ou de "alemão batata" (no caso dos alemães). Neste artigo, estamos nos referindo especificamente aos universos por nós pesquisados e que tiveram como protagonistas, em sua quase totalidade, italianos descendentes de imigrantes provenientes do norte da Itália.

Entre os descendentes de imigrantes italianos da região central do estado, o risoto é um alimento extremamente valorizado e para o qual há vários procedimentos no preparo. Os acompanhamentos do mesmo tendem a ser 
diferenciados conforme a posição social do descendente, variando em função de sua inserção nas camadas urbanas ou no meio camponês. O tamanho das porções, igualmente, no meio camponês, tende a ser muito maior que nos cenários dos descendentes urbanos. $O$ risoto costuma ser feito por partes: primeiro se cozinha o brodo, o caldo, feito com carne de galinha fervida com alguns temperos, tais como sal, manjerona, cebola, alho e pimenta. Contudo, há variações no preparo do brodo. Quando o brodo estiver no ponto, retira-se a carne (que se transforma em carne lessa), acresce-se o arroz e se mexe até que ele esteja no ponto, al dente, ou seja, ainda firme. No final, acrescenta-se manteiga e queijo parmesão, mexe-se uma última vez e deixa-se abafar um pouco. É um alimento que pode ser comido como prato principal ou entrada quente. Come-se com pão, pois a textura do mesmo é cremosa.

A minestra, um tipo de sopa que mistura feijão preto e legumes, é considerada contemporaneamente como comida "de pobre" e não é tão bem vista em mesas de descendentes de classes médias urbanas, sendo substituída frequentemente pela sopa de capeletti ou agnolini ${ }^{12}$. Trata-se de um alimento ainda bastante apreciado nos dias atuais, mas com o caráter de prato de entrada e não mais como prato principal, como era no passado, principalmente entre os camponeses que utilizavam as sobras do almoço para elaborarem a minestra no jantar.

A polenta, contudo, conforme observado por Zanini (2006) tende a ser um alimento presente na mesa de descendentes de classes sociais variadas, especialmente quando é servida frita. Sobre a polenta, há uma variedade de técnicas de preparo e de formas de consumo. Com as novas farinhas de milho instantâneas e pré-cozidas (as polentinas, como são chamadas) presentes hoje no mercado, a produção de uma boa polenta mudou de foco. Se no passado começar a polenta com água fria e um pouco de farinha para não "embolotar"13 era um pré-requisito da boa esposa, hoje, com as farinhas novas, as descendentes ressaltam que pouca diferença faz começar com água fria ou quente. Por uma questão de praticidade, a farinha para a polenta costuma ser alternada: quando há farinha caseira ou de algum moinho próximo, utiliza-se daquela que requer ser começada com água fria e, na falta desta farinha, usa-se a industrializada, que dispensaria tal cuidado. Uma entrevistada ressaltou: "O que não pode faltar é a polenta".

O galeto, feito com frangos novos é oriundo do hábito dos primeiros descendentes de se alimentarem de pássaros, sendo comumente encontrado em mesas diversas. No entanto, o churrasco, considerado uma comida de "gaúchos" (denominação atribuída regionalmente aos habitantes do Rio Grande do Sul) também é presença constante na mesa dos descendentes de imigrantes italianos, especialmente no almoço dos domingos e nas datas festivas. $O$ gosto pela carne no espeto e assada na brasa ao estilo gaúcho do sul do Brasil, a exemplo do churrasco, ingressou no gosto dos imigrantes italianos e seus descendentes desde os primórdios da colonização. Os complementos do churrasco de 
domingo, por exemplo, costumam ser a maionese (como é denominada a salada de batatas cozidas na água e escorridas e temperada com maionese feita de ovos e outras especiarias), o pão, a polenta frita ou brustulada (assada na chapa do fogão a lenha), saladas verdes, mandioca cozida na água, arroz ou risoto e bebidas. $O$ galeto também é assado no espeto e cozido com o calor das brasas e os acompanhamentos costumam ser os mesmos do churrasco, contudo, neste, a polenta frita ou assada é obrigatória. Na região central do estado, foi observada uma grande variedade de formas de preparo, de tempero e também de cozimento dos alimentos. Uma das justificativas atribuídas ao "jeito de fazer" da família ou do descendente era o aprendizado via socialização, bem como o ingresso de ingredientes e novas técnicas consideradas positivas, especialmente após a entrada de utensílios e eletrodomésticos no universo das cozinhas, fato também observado por Simonetti (2011) entre camponesas descendentes de italianos.

Importante elemento presente e obrigatório nos gostos alimentares dos descendentes de italianos são as saladas e as ervas aromáticas (em especial a sálvia, a manjerona e o manjericão). Uma verdura extremamente valorizada é o radici, comparado ao almeirão. Trata-se de uma folha com gosto um pouco amargo, que é temperada com vinagre, óleo e outras especiarias e servido junto à polenta e aos demais alimentos. Há vários tipos de radici (folha larga, folha fina, pão de açúcar, amarelo, roxo, entre outras), sendo comum a troca dessas sementes entre os descendentes. Em pesquisa de campo recente, Zanini foi informada que há um tipo de radici que é muito cobiçado e que poucos produtores e famílias ainda teriam na região central do estado. Ele seria uma espécie mais "arredondada" e considerada do "tempo dos antigos". Há toda uma rede de informações que se estabelece para saber quem detém as sementes, quem planta, se as vende ou não, ou seja, esta tende a ser uma informação bastante valorizada entre os descendentes, especialmente os do mundo rural, mas não só. Zanini tem encontrado descendentes, habitantes do mundo urbano da cidade de Santa Maria, que se deslocam "à colônia" para adquirir produtos considerados mais saudáveis e elaborados de acordo com o modo colonial de seus antepassados.

O pão é outro alimento indispensável nas mesas dos descendentes de italianos. Há uma variedade de formas de preparo e também de misturas. 0 mais comum é o branco, sovado, feito com ovos, farinha de trigo, sal, açúcar, fermento biológico e leite. Contudo, pode-se fazê-lo mais doce ou com outras misturas, como milho, mandioca amassada e, na contemporaneidade, farinhas integrais e cereais. Zanini (2006) encontrou descendentes que ainda utilizavam o fermento oriundo da fermentação da batata, como faziam seus ancestrais. 0 pão é consumido tanto no café da manhã como no almoço e no jantar. Ele é um complemento fundamental e indispensável. Pelas narrativas, observa-se que a polenta, no passado, ocupava o papel de alimento básico em todas as refeições, o que hoje é dividido com o pão, o feijão e o arroz. Ou seja, os descendentes, em 
suas dinâmicas interativas com as sociedades envolventes, trocaram e dialogaram as comensalidades vizinhas. Um exemplo disto foi a incorporação da mandioca enquanto comida e alimento bastante presente nas mesas dos descendentes de italianos.

Outro aspecto importante de ser ressaltado é acerca de novos hábitos que, igualmente, os imigrantes italianos e seus descendentes introduziram entre as populações com as quais avizinharam. Um dos relatos coletados por Zanini ressalta que o italiano procurava plantar e produzir praticamente toda sua comida em casa, por meio da utilização da mão de obra familiar, o que causava estranhamento nas populações nativas de algumas localidades do Rio Grande do Sul:

[...] vinha da horta, do pomar; a parreira já existia [...] o próprio fabrico de roupa, de calçados, comida...; eu não vivi muito isso, mas no meio italiano, por exemplo, o açúcar mascavo, o melado, a cachaça, o vinho, tudo era praticamente feito; o leite, o porco, a galinha..., quem é que criava galinha? Isso também é outro estilo, o brasileiro não sabia, o máximo que fazia era deixar solto... O meu pai foi um dos primeiros a ter horta... Então, eu me lembro assim, eu me abismava que os caras iam pra lá e enchiam, por exemplo, os carros de agrião, que não conheciam; de radici, que não conheciam; de rúcula, que não conheciam... Essa horta, melancia, eu tinha o quê?, sete, oito, dez anos..., junto com o pai e meus irmãos, enchia aqueles carroção de melancia e vendia na cidade, porque não se plantava melancia. Outra coisa, meu pai foi um dos primeiros a ter trator... em [19]58...

(Descendente, homem, próximo aos setenta anos, morador urbano de Santa Maria).

Na Serra Gaúcha, a comida está presente principalmente nos apelos turísticos que sempre destacam a fartura das mesas e aparece também na "Festa da Uva", uma das principais celebrações do município de Caxias do Sul, que chama atenção pela farta distribuição de uvas e também pelo significado que é atribuído à alimentação nos seus desfiles. $O$ vinho, também considerado comida entre os descendentes de italianos, converteu-se em símbolo migratório na serra gaúcha, o que não aconteceu na região central do estado. Contudo, mesmo não sendo grandes produtores de vinho, os descendentes de italianos desta região são grandes consumidores da bebida, que importam de "Caxias"14. Alguns, inclusive, importam as uvas de "Caxias" e fabricam domesticamente seu próprio vinho. O queijo, igualmente, é um dos alimentos mais valorizados e apreciados e sobre sua feitura há toda uma classificação acerca do sabor, da textura, do aroma. Há descendentes que reconhecem a procedência do queijo pelo aroma e sabor e o classificam como queijo da família x ou y. 
Fazer da comida um elemento de exposição e de adscrição é interessante, pois, além de simbolizar uma migração que potencialmente deu certo e que pode se autossustentar, afasta-se o estigma da "fome" que acompanhou gerações de camponeses na Europa e, em algumas situações, no Brasil também. Na região central do estado foi criada, há poucos anos, a Rota Gastronômica, que atravessa alguns municípios da IV Colônia de Imigração Italiana, como é denominada a região de colonização italiana (e também alemã) desta parte do estado e na qual a comida é o maior atrativo. $O$ turismo, igualmente, tem sido um estimulador da utilização da comida como fronteira adscritiva das italianidades e potencializado novas discursividades acerca dos saberes e fazeres que acompanham a feitura e exposição dos alimentos.

Enfim, o que os estudos apontaram é que a comida, o alimento e as comensalidades foram e ainda são extremamente importantes no cotidiano dos imigrantes italianos e seus descendentes no Rio Grande do Sul. Esta importância faz como que ela seja tratada, pelos próprios descendentes, como um patrimônio, um bem que significa a manutenção de uma identidade étnica e cultural distinta das dos demais brasileiros. Zanini (2006), em suas visitas a famílias de descendentes, destacou o quanto a oferta de alimento e de produtos por eles elaborados era um sinal de agrado e de estima pela pessoa a ser recebida. A comida pode variar, mas a relação que ela procura estabelecer com o outro, não.

\section{Considerações Finais}

Entre os descendentes de italianos por nós estudados, observa-se que a comida e seus domínios ainda são majoritariamente femininos, embora alguns homens, especialmente das camadas médias urbanas, têm se aventurado no espaço das cozinhas. Os negócios que envolvem alimentos ainda continuam majoritariamente masculinos. Nas feiras urbanas em Santa Maria, por exemplo, observam-se famílias inteiras de agricultores comercializando seus alimentos, contudo, percebe-se que a autoridade masculina é algo extremamente marcante na formulação dos preços e no desfecho de negociações com consumidores urbanos. Este quadro, conforme pesquisa recente de Zanini, tem se alterado e algumas (poucas) mulheres têm sido protagonistas na arte de negociar nas feiras.

O que se averigua é que, desde o início do processo colonizador no Rio Grande do Sul, as comensalidades, os gostos, posturas e trato com relação aos alimentos desempenharam papel extremamente importante na fixação daquelas populações nas colônias. O símbolo da família italiana com suas mesas fartas foi algo que se desenvolveu no processo colonizador, como símbolo adscritivo e, talvez, como elemento demarcador justificando sua permanência em terras brasileiras.

O que se pode ressaltar é o caráter dinâmico e complexo que envolve os alimentos, desde o seu plantio, a colheita e o ato da alimentação. $O$ alimento para casa ou o alimento "para fora" é algo classificado de forma distinta pelos 
produtores, o que nos leva a refletir acerca da complexidade presente nas relações em que o alimento é, também, fonte de renda. Além disso, no presente, não se pode esquecer o papel importante que o turismo tem desempenhado para os colonos italianos. Nesta atividade, igualmente, a comida se converte num grande atrativo e sinal adscritivo em que deixar à mostra o excesso de alimento se converte numa fonte de orgulho e honra. Neste aspecto, observa-se que a comida pode, por vezes, ser importante patrimônio a ser requisitado, uma vez que nela residem formas de saberes e de fazeres específicas por meio das quais os indivíduos se percebem como sujeitos.

\section{Notas}

1 - Tradução das autoras: "Come, que te faz bem!", ditado muito comum entre descendentes de imigrantes italianos.

2 - Uma versão inicial deste artigo foi apresentada no VIII Congresso Latino-americano de Sociologia Rural, em porto de Galinhas, 2009. A versão que aqui se apresenta passou por alterações e novas reflexões oriundas de trabalho de campo realizado em 2011.

3 - Colônia é o designativo atribuído aos espaços de terra delegados pelo governo brasileiro aos imigrantes italianos para colonizarem tais regiões.

4 - Há variação na elaboração dos grostolis, em especial na textura da massa, se grossa ou fina. São "bolachas" grandes, cruzadas ao meio, fritas e adoçadas com canela e açúcar. Segundo uma entrevistada, que fazia o grostoli fino, grostoli grosso era coisa "de preguiçoso".

5 - Capeletti é uma massa recheada com carne de gado, frango, miúdos, salame ou outros recheios, em forma de chapéu. Pode ser usada na sopa ou fazer "ao molho".

6 - Quando nos referimos a italianos ou italianas, ressaltamos que são formas narrativas de autorreferência. Em verdade, a quase totalidade dos entrevistados é descendente de italianos e são nascidos no Brasil. Alguns possuem a dupla cidadania, outros não. Mas, isto não impede que se sintam "italianos".

7 - Aqueles que são de casa.

8 - Tradução livre das autoras.

9 - Tradução livre das autoras.

10 - Esta novela apresentava a travessia dos emigrados italianos, sua chegada ao Brasil (em São Paulo), seu trabalho nos cafezais e a vinda para São Paulo. Trata-se de uma novela que foi bastante assistida pelos descendentes de imigrantes italianos no Rio Grande do Sul (vide ZANINI, 2005).

11 - Depoimento gravado por Santos no dia 1/3/2002.

12 - Segundo Ribeiro (1998, p. 188), a sopa típica da região por quase um século foi a minestra, uma sopa de verduras com feijão que normalmente servia de jantar para a maioria dos colonos. Só bem mais tarde se populariza a sopa de agnolini ou capeletti (a diferença entre o agnolini e o capeletti é somente o formato da massa). Ver também Zanini, 2006.

13 - Criação de bolas duras com farinha seca em seu interior. Estas bolas devem ser desmanchadas para que a polenta seja considerada de boa qualidade. É uma vergonha para uma mulher servir uma polenta mal misturada.

14 - Por Caxias, entende-se toda a região serrana do Rio Grande do Sul. Trata-se de um termo nativo para se referir àquela região do estado em comparação à região central.

\section{Referências}

ALVIM, Zuleika Maria Forcione. Brava gente! Os italianos em São Paulo 1870-1920. São Paulo: Brasiliense, 1986. 
BARTH, Frederik. Os grupos étnicos e suas fronteiras. In: LASK, Tomke. (org.) O guru, o iniciador e outras variações antropológicas. Rio de Janeiro: Contra Capa Livraria, 2000.

BOURDIEU, Pierre. Questões de sociologia. Rio de Janeiro: Marco Zero, 1983.

BOURDIEU, Pierre. A dominação masculina, Bertrand Brasil: Rio de Janeiro, 1999.

COSTA, Rovílio et al. Imigração italiana no Rio Grande do Sul. Porto Alegre: EST; Caxias do Sul: EDUCS, 1986.

DaMATTA, Roberto. 6 ed .o que faz o brasil, Brasil? Rio de Janeiro: Rocco, 1993.

DE BONI, Luis Alberto. O catolicismo da imigração: do triunfo à crise. In: LANDO, Aldair et al. (org). Migração \& Colonização. Porto Alegre: Mercado Aberto, 1980, p. 234-255.

DE BONI, Luis Alberto e COSTA, Rovílio. Os italianos do Rio Grande do Sul. 2 ed. Porto Alegre/ Caxias do Sul: EST/Universidade de Caxias do Sul, 1982.

DE BONI, Luis Alberto (org.) A presença Italiana no Brasil. Porto Alegre: EST, 1987.

DOUGLAS, Mary. Deciphering a meal. In: GEERTZ, Clifford (org.). Myth, Symbol, and culture. Nova York: Norton, 1971.

FAVARO, Cleci Eulália. Imagens femininas: contradições, ambivalências, violências. Porto Alegre: EDIPUCRS, 2002.

FISCHLER, Claude. L'Homnivore . Paris: Odile Jacob, 2001.

GEERTZ, Clifford. A Interpretação das culturas. Rio de Janeiro: LTC, 1989.

GROSSELI, Renzo Maria. Vencer ou morrer. Camponeses trentinos (vênetos e lombardos) nas florestas brasileiras. Florianópolis: Editora da UFSC, 1987.

HALBWACHS, Maurice. A memória coletiva. São Paulo: Vértice / Editora Revista dos Tribunais, 1990.

LORENZONI, Julio. Memórias de um imigrante italiano. Porto Alegre: Sulina, 1975.

MACHADO, Paulo Pinheiro. A política de colonização do Império. Porto Alegre: Edufrgs, 1999.

MACIEL, Maria Eunice. Cultura e alimentação ou o que tem a ver os macaquinhos de Koshima com Brillat-Savarin? Horizontes Antropológicos, Porto Alegre, ano 7, n.16, p.145-156, dez., 2001.

MINTZ, Sidney W. Sweet, salt and the language of love. In: $M L N$, v. 106, n. 4. p. 852-860, set. 1991. Disponível em: <http://www.jstor.org/stable/2904627>. Acesso em: 20 ago. 2008.

MINTZ, Sidney. Comida e antropologia. Uma breve revisão. Revista Brasileira de Ciências Sociais, São Paulo, v. 16, n.47, p.31-41, out., 2001.

MINTZ, Sidney e DU BOIS, Christine. The anthropology of food and eating. Annual Review of Anthropology, v. 31, p. 99-119, out., 2002. Disponível em: <http://www.jstor.org/ stable/4132873>. Acesso em: 20 ago. 2008.

POULAIN, Jean-Pierre. Sociologia da alimentação. Florianópolis: UFSC, 2006.

POZZOBON, Andréa. Uma Odisséia na América. In: POZZOBON, Zolá Franco. Uma odisséia na América. Caxias do Sul: EDUCS, 1997.

RIBEIRO, Cleodes Maria Piazza Júlio. Festa \& Identidade: como se fez a festa da uva. Caxias do Sul: EDUCS, 2002.

SANTOS, Miriam de Oliveira. Bendito é o Fruto: Festa da Uva e Identidade entre os Descendentes de Imigrantes Italianos de Caxias do Sul/RS. Rio de Janeiro, Tese de doutoramento, PPGAS/ Museu Nacional, UFRJ, 2004.

SEYFERTH, Giralda. Identidade camponesa e identidade étnica (um estudo de caso). Anuário Antropológico 91. Rio de Janeiro: Tempo Brasileiro, p. 31-63, 1993.

SIMONETTI, Fernanda. Mamma Mia: a compreensão do saber fazer cotidiano e a ressignificação dos papéis entre mulheres camponesas. Santa Maria, Dissertação de Mestrado, PPGCS/ UFSM, 2011.

WOORTMANN, Ellen. Padrões tradicionais e modernização: comida e trabalho entre camponeses teuto-brasileiros. In: MENASCHE, Renata (org). A agricultura familiar à mesa: saberes e práticas da alimentação no vale do Taquari. Porto Alegre: Editora da UFRGS, 2007, p.177-196. 
ZANINI, Maria Catarina Chitolina. Assistir, ouvir, ler e narrar: o papel da mídia nas construções identitárias étnicas. Revista de Antropologia (USP), São Paulo, v. 48, n. 2, p. 699-736, jul./ dez. 2005.

ZANINI, Maria Catarina. Italianidade no Brasil meridional. A construção da identidade étnica na região de Santa Maria/RS. Santa Maria: Ed.UFSM, 2006.

ZANINI, Maria Catarina e SANTOS, Miriam de Oliveira. O trabalho como "categoria étnica": um estudo comparativo da ascensão social de imigrantes italianos e seus descendentes no Rio Grande do Sul (1875-1975). REMHU, Brasília, Ano XVII, n. 33, p.175-196, jul./dez. 2009.

\title{
RESUMO
}

Neste artigo, analisamos o papel da comida para os descendentes de italianos que migraram para o Rio Grande do Sul em finais do século XIX e início do século XX. No sul do Brasil, os imigrantes europeus se instalaram em pequenas colônias que, embora dentro dos parâmetros da política de colonização brasileira, buscavam reproduzir o modelo camponês europeu. Esses imigrantes eram, em sua maioria, camponeses pobres, católicos e provenientes do norte da Itália. Uma migração familiar marcada pela expectativa da cucagna, da terra em que os salames nasceriam em árvores e a conquista da riqueza seria uma questão de tempo e algum trabalho. Ou seja, além de ascenderem socialmente e tornarem-se proprietários, aquelas populações queriam comida e a queriam em abundância. Acreditamos que a ênfase na fartura representa a prosperidade e o desejo de perpetuá-la, mas também sinaliza para a diferenciação cultural e a simbologia da migração que deu certo.

Palavras-chave: identidade étnica; comida étnica; diferenciação cultural.

\begin{abstract}
In this article we analyze the role of food for the descendants of Italians who migrated to Rio Grande do Sul in the late nineteenth and early twentieth century. In southern Brazil, European immigrants settled in small colonies, even within the parameters of the policy of colonization of Brazil, sought to replicate the European rural model. These immigrants were mostly poor peasants, Catholics and of northern-italian origin. This family migration was marked by the expectation of cucagna too: the land where the salamis grow on trees and the conquest of wealth would be a matter of time and some work. That is, apart from rising socially, to become owners, these people wished food and wanted it in abundance. We believe that the emphasis on prosperity and abundance represents the desire to perpetuate it, but also points to cultural differentiation and the symbolism of successful migration.
\end{abstract}

Keywords: ethnic identity; ethnic food; cultural differentiation. 
